\title{
Clinical and Research Advances in Huntington's Disease
}

\author{
M. SuttonBrown, O. Suchowersky
}

\begin{abstract}
Huntington's disease (HD) is an autosomal dominant neurodegenerative disorder characterized by abnormalities of movement and dementia. No curative treatment is available and HD results in gradually increasing disability. Characterization of the genetic abnormality has dramatically increased our understanding of the underlying mechanisms of the disease process, and has resulted in the development of a number of genetic models. These research tools are forming the basis of advanced work into the diagnosis, pathophysiology, and potential treatment of the disease. Clinically, the availability of genetic testing has eased confirmation of diagnosis in symptomatic individuals. Presymptomatic testing allows at-risk individuals to make informed choices but requires supportive care from physicians. Current clinical treatment is focused on symptom control. Advances in research have resulted in the development of potential neuroprotective strategies which are undergoing clinical testing.
\end{abstract}

RÉSUMÉ: Progrès en clinique et en recherche sur la maladie de Huntington. La maladie de Huntington (MH) est une maladie neurodégénératrice dominante autosomique caractérisée par des mouvements anormaux et une démence. Il n'existe aucun traitement curatif de cette maladie qui conduit à une invalidité progressive. La caractérisation de l'anomalie génétique a accru significativement notre compréhension des mécanismes sous-jacents et a mené au développement de modèles génétiques. Ces outils de recherche constituent la base du travail actuel sur le diagnostic, la physiopathologie et les avenues de traitement de la maladie. Au point de vue clinique, la disponibilité du test génétique a facilité la confirmation du diagnostic chez les individus symptomatiques. Le test présymptomatique permet aux individus à risque de faire des choix éclairés mais demande du soutien de la part des médecins. Le traitement actuel de la maladie vise le contrôle des symptômes. Les progrès de la recherche ont permis de développer des stratégies neuroprotectrices potentielles qui font présentement l'objet d'essais thérapeutiques.

Can. J. Neurol. Sci. 2003; 30: Suppl. 1 - S45-S52

Huntington's disease (HD) is a progressive neurodegenerative disorder characterized by choreiform movements, psychiatric changes, and dementia. ${ }^{1}$ It is inherited in an autosomal dominant fashion as described by Dr. George Huntington in his seminal paper published in $1872 .^{2}$ Invariably, patients who inherit the fully expanded genetic mutation develop the clinical manifestations of HD. Disease progression is gradual but relentless, resulting in gradually increasing disability.

The prevalence of HD is estimated to be five to eight per 100,000 in Europe and North America and is much less common in non-European ethnic groups. ${ }^{3}$ Lineage tracing of affected individuals living in eastern United States in 1932 showed a common ancestry to one village in England. ${ }^{4}$ However, it is speculated that a number of spontaneous mutations likely occurred throughout Europe, producing several genetic founders. The late age of onset is one explanation for the dissemination of the HD mutation.

\section{Clinical features AND diagnosis}

The age of onset of HD is variable, with the mean being from the late thirties to early forties. Childhood onset has been reported to be as young as five years, with the oldest patients presenting in their seventies. ${ }^{1}$ In general, the age of onset for family members tends to be similar, but no specific predictions can be made for a given individual.

The clinical presentation of HD is characterized by chorea, a rapid and involuntary arrhythmic contraction involving the face, trunk, and limbs. Typically, the contractions are distinct, nonrepetitive, and longer in duration than myoclonus. The chorea worsens with anxiety. In advanced cases, it can affect the diaphragm and vocal apparatus, producing an explosive dysarthria. The patient may mask early behaviours by integrating them into purposeful actions and confabulate about their

From the Departments of Clinical Neurosciences (MSB, OS), and Medical Genetics (OS), University of Calgary, Calgary, ABCanada

Reprint requests to: Oksana Suchowersky, Department of Clinical Neurosciences, Area 3, 3350 Hospital Dr. NW, Calgary, AB Canada T2N 4N1 
presence. This stands in contrast with most other movement disorders, where the abnormal movements are more intrusive to the patient. In addition, chorea is often intermixed with other motor abnormalities, such as dystonia. Eye movement testing reveals saccadic smooth pursuit, poor optokinetic nystagmus, and slowness with refixation. Hypotonia with hyperreflexia is a feature of early disease. With disease progression, bradykinesia and rigidity become prominent. Other features include abnormalities of gait, dysphagia, and urinary incontinence with eventual compromise of activities of daily living.

Another feature is cachexia which occurs in spite of adequate caloric intake. The hyperkinetic state combined with abnormalities of muscle or adipose tissue metabolism is the postulated explanation. ${ }^{5,6}$

Abnormal cognition is invariably a feature of HD and may predate motor symptoms. Abnormalities, such as irritability and depression are common early in the course of the disease. ${ }^{7}$ Occasionally, patients may be misdiagnosed with psychiatric diseases like schizophrenia and delusional disorder. Late stage disease is characterized by significant and disabling 'subcortical' dementia, characterized by deficits in time based tasks like word fluency, picture sequencing, and the Wisconsin card sorting test. ${ }^{8}$ Patients rarely show signs of aphasia or apraxia; memory loss is seen only in late stage disease.

Juvenile HD is defined by onset before age twenty. The clinical presentation differs significantly from that in adult onset populations (Table 1). Bradykinesia is combined with severe cognitive deficits. The wide range of clinical findings, such as the occurrence of epilepsy and myoclonus, can make diagnosis difficult if a clear family history is not available.

In late onset patients, chorea is a prominent feature, with minimal cognitive dysfunction. ${ }^{1}$ Rarely, late onset HD may mimic levodopa responsive parkinsonism. ${ }^{9}$

Regardless of age of onset, HD is a chronic progressive disease. The slow but unyielding deterioration of the patients' cognitive and motor symptoms causes significant morbidity and early mortality. Complications of immobility, such as aspiration pneumonia and other infections, cause death 10 to 30 years after disease onset.

\section{DIFFERENTIALDIAGNOSIS AND INVESTIGATIONS}

Although the genetic test for HD allows us to determine who carries the gene, diagnosis of symptomatic disease remains based on detailed neurological assessment. Alternative diagnoses should always be considered. For example, tardive dyskinesia may be mistaken for chorea in an at-risk individual on neuroleptics. (See Table 2 for detailed list of causes of chorea).

Imaging is not diagnostic of HD but is useful in excluding other pathologies such as ischemic caudate lesions, Hallevorden-Spatz disease, or multiple sclerosis. Caudate atrophy is well-known to be present in advanced $\mathrm{HD}$, but recent studies using serial CT scanning of the basal ganglia in asymptomatic at-risk individuals indicates progressive atrophy predating symptomatic disease..$^{10,11}$ PET studies indicate changes in metabolism of the caudate correlating with clinical decline, supporting theories of metabolic dysfunction. ${ }^{12-14}$ More recent studies using MRI - BOLD (blood oxygen level dependent) have shown that an abnormal cortical signal during cognitive tasks is associated with disease. ${ }^{15}$

Table 1: Juvenile Huntington's disease

\begin{tabular}{ll}
\hline Clinical features & \\
rigidity & spasticity \\
bradykinesia & cerebellar abnormalities \\
chorea absent or minimal & myoclonus \\
dementia - rapidly progressive & epilepsy \\
\end{tabular}

Table 2: Differential diagnosis of chorea

\section{A. Hereditary}

a) autosomal dominant Huntington's disease benign hereditary chorea familial paroxysmal kinesogenic choreoathetosis

familial paroxysmal dystonic choreoathetosis

pseudo/pseudopseudo hypoparathyroidism

dentato-rubro-pallidoluysian atrophy

b) autosomal recessive neuronal lipofuscinosis Wilson's disease late onset Pelizeus-Merbacher disease

Nieman-Pick disease Lesch-Nyhan disease Hallervorden-Spatz disease

c) maternal inheritance mitochondrial cytopathy

\section{B. Auto Immune}

Sydenham's chorea

chorea gravidarum

systemic lupus erythrometosis

periateritis nodosa

Behcet's disease

multiple sclerosis

antiphospholipid syndromes

\section{Neoplasia}

basal ganglia involvement paraneoplastic syndrome

D. Vascular

infarct

arterio-venous malformation

\section{E. Infectious}

diptheria

neurosyphilis

Lyme disease

Legionnaire's disease

encephalitis

AIDS

Creutzfeldt-Jakob disease sarcoidosis

\section{F. Metabolic}

hypo/hypernatremia hypocalcemia

hypohyperglycemia

hyperthyroidism

hepatocerebral degeneration renal failure

thiamine deficiency niacin deficiency hypoparathyroidism polycythemia

\section{G. Toxins}

alcohol

carbon monoxide

mercury

manganese

\section{H. Drugs}

neuroleptics antiparkinsonian medications anticonvulsants amphetamines steroids opiates tricyclic antidepressants lithium digoxin cocaine 


\section{Genetics}

The genetic abnormality of HD results from the increase in number of cytosine, adenine, and guanine (CAG) repeat sequences in exon 1 of the HD gene on chromosome $4 .{ }^{16}$ This gene, now known as interesting transcript 15 (IT 15), codes for the protein huntingtin (htt). It has little homology with other protein classes and the function is not known. Interesting transcript 15 is expressed throughout the body with especially high concentrations in the brain, testis, ovaries, and lungs. ${ }^{17}$ The CAG repeat produces a polyglutamate (polyQ) stretch at the Nterminus of htt and the clinical disorder is only seen after the number of CAG repeats passes the disease threshold of $\geq 38$. Repeat numbers are inversely correlated with the age of onset, with juvenile HD patients having a repeat expansion size of 50 or greater. ${ }^{18}$ Rate of disease progression is also greater with a larger repeat size. ${ }^{19}$ The number of CAG repeats may increase between generations and is reflected in a shift towards earlier ages of disease onset, termed anticipation. The average increase in repeat number for paternal and maternal transmission is 0.4 and 9 repeats per generation respectively. ${ }^{20}$ Decreases in the number of CAG repeats rarely occur, and only in maternal transmission.

Mutant IT15 is dominant with full penetrance but with a variable time of onset. There is no additional effect of a second copy of mutant HD with the longer repeat being predictive of the age of onset and severity of disease. ${ }^{21}$ Sporadic cases of HD have been documented and may be due to one parent having a borderline number of CAG repeats (34-37 repeats) producing HD offspring through expansion during transmission. ${ }^{22}$ However, most cases can be explained by alternative means (nonpaternity, misdiagnosis, denial, premature death of the affected parent).

Genocopies of HD have recently been described, ${ }^{23-28}$ although the exact genetic abnormalities have yet to be determined. An exception is the HD-like 2 locus where a CAG/CTG repeat expansion is described in the gene encoding junctophilin-3. ${ }^{28}$ A large degree of heterogeneity in those negative for the HD mutation appears to be present, and offers an exciting opportunity to ask important questions about the homology of these mutations at the genetic and molecular level.

\section{Mouse MODELS}

One of the recent advancements in HD research has been the development of transgenic animal models now being used to investigate the etiology, pathogenesis, and potential treatment mechanisms for HD. Currently, there are five main types of transgenic HD mouse models: R6/2, ${ }^{29} \mathrm{~N} 171,{ }^{30} \mathrm{HD} 48 / 49,{ }^{31}$ yeast artificial chromosome (YAC), ${ }^{32}$ and knock-in models. ${ }^{33-36}$ The different models display significant differences in their movement disorder, cognitive effects, neuropathology and age of onset.

The R6/2 mice lines were created using a fragment of the human HD gene containing a promoter and exon 1 (62 amino acids) with the CAG expansion repeats. ${ }^{29}$ The model exhibits a progressive motor disorder mixed with cognitive decline. ${ }^{37,38}$ Schilling et al $^{30}$ developed the N171 mouse model by inserting a gene coding for 171 amino acids of the human htt protein and including 82 CAG repeats (N171-82Q). The entire gene is expressed at a basal rate. The HD48 model was created by similar methods as the N171 model. ${ }^{31}$ In this case, a coding DNA strand was created for the entire human htt protein, producing a significantly different phenotype compared to the N171 and R6/2 lines. The YAC mouse model was created to provide a means of using the entire human HD gene with it's own regulatory mechanisms intact. ${ }^{32}$ This variation produced a wide range of expression and a variable phenotype that is difficult to reconcile with our understanding of HD.

Knock-in mice have been developed by several methods. ${ }^{33-36}$ In all of these studies, the corresponding HD gene in mice (Hdh) is modified to include increased CAG repeats. This modification is performed by inserting either a pure mouse gene or a HD/Hdh chimera. There are a number of potential benefits from this approach as compared to the other transgenic animal models. By using the mouse promoter, these models produce the gene product at endogenous levels. Furthermore, the distribution of the gene product is the same as compared to the controls, further isolating the effect of the CAG expansion. Unfortunately, these models do not produce the dramatic phenotype seen in other animal models. In addition to mouse models, others have created animal models using Drosophila and C. elegans. ${ }^{39,40}$ The variability in their unique approaches provides opportunities to explore different aspects of the HD pathophysiology.

\section{Genetic TeSTing}

The easy availability of a simple, sensitive, and specific test for $\mathrm{HD}$ has allowed for rapid confirmation of the clinical diagnosis of HD. Testing is also available for asymptomatic atrisk individuals. Approximately $20 \%$ of at-risk individuals make use of this type of testing in order to plan their future and make decisions with respect to child bearing. Presymptomatic testing should be done only at Genetics Centers with experienced geneticists and counselors and appropriate psychosocial support. Risk of suicide and other "catastrophic events" have been closely studied in this population, and shown to be low with appropriate support [worldwide risk $0.97 \%$ ]. ${ }^{41}$ However, the psychological effects of the testing, such as depression, may last up to one year after receiving results. Although these are seen more commonly in those who test positive, they may also occur in the setting of negative results. A psychiatric history and unemployment are significant risk factors for a less satisfactory outcome. Prenatal testing is also available, but its use has been below expectations $(9-15 \%){ }^{42}$

\section{NEUROPATHOPHYSIOLOGY}

In advanced HD, prominent atrophy is seen in the frontal lobes, caudate nucleus, putamen, globus pallidus, cerebellar cortex, pons, and amygdala. ${ }^{43-46}$ The most significant changes are seen in the striatum where a caudal to rostral, dorsal to ventral, and medial to lateral pattern of neuron loss is seen. The medium spiny GABAergic neurons are the primary cell type affected in the striatum, perhaps due to the high levels of expression of htt. ${ }^{17}$ Research efforts have focused on models of excitotoxic neuron loss, alterations in gene expression, altered function or metabolism of htt, and mitochondrial toxicity. Each of these approaches has had some success and is not mutually exclusive. 
The excitotoxic effects of glutamatergic transmission have been a proposed etiology of HD. ${ }^{47}$ Glutamate, and its analogs, have been heavily utilized as excitotoxins in the creation of HD animal models since kainic acid was first used in $1976 .{ }^{48}$ Quinolinic acid (QA), in particular, is selective in its over activation of glutamate receptors, sparing medium sized aspiny neurons. ${ }^{49,50}$ In addition, QA is an endogenous metabolite leading some to question if HD increases neuron sensitivity to this native toxin. ${ }^{51}$ Studies continue to support the strong similarities of neurochemistry, anatomic lesion, movement disorder, and temporal profile between the HD and QA lesions. ${ }^{52,53}$. However, the value of the excitotoxic models has recently come into question, as studies in human and genetic animal models have found clinical dysfunction with little neuronal loss. ${ }^{54}$

Huntingtin is a necessary part of embryonic development in mice but is not required for growth and neuronal differentiation..$^{55,56}$ Furthermore, analysis of changes seen in knock-out mice have revealed strong evidence for a role for htt in iron homeostasis, maintenance of perinuclear organelle structure, and trafficking of secretory membrane. ${ }^{57}$ In addition, genetic models of HD have shown changes in related gene expression. ${ }^{58}$ It remains unclear how the mutant IT15 gene might affect this. Saudou et $\mathrm{al}^{59}$ showed that the polyQ component of htt is only toxic when localized to the nucleus, where it can interact with regulation factors.

Transcription of brain-derived neurotrophic factor, which has a protective function, has been found to be modulated by wildtype htt. ${ }^{60}$ Mutant htt has been shown to be less effective at maintaining brain-derived neurotrophic factor levels, providing one mechanism for producing a proapoptotic state in HD. More recently, mutant htt has also been found to inhibit the action of Sp1, a transcription activator. ${ }^{61}$ Interestingly, the lethal effect of htt was mitigated by separately modulating the expression of this inhibited factor. This provides another potential site for therapeutic intervention.

Studies of HD patients have previously described nuclear inclusions (NI) or neuronal intranuclear inclusions. ${ }^{62,63}$ Nuclear inclusions are protein aggregates that appear in the intranuclear space of neurons in HD, genetic mice models, and other polyQ disorders, and are immunoreactive for the N-termini of htt and ubiquitin. $^{64}$ Their formation has been associated with nuclear membrane indentations and alterations in nuclear pore numbers and configuration. ${ }^{65,66}$ Nuclear inclusions could represent the neurons' inability to completely degrade the mutant htt protein. Davies et al, ${ }^{62}$ using genetic mice models, demonstrated NI in only those strains exhibiting an abnormal phenotype. In addition, the localization of htt and ubiquitin within the nucleus predates clinical changes, further supporting a strong association between NI formation and the pathogenesis of the clinical disorder. Increases in polyQ repeats have also been associated with increasing numbers of NI, offering a possible explanation for the correlation between $\mathrm{CAG}$ repeat length and age of disease onset. ${ }^{63}$

An alternative explanation is that NI are the product of the neuron's protective response to un-ubiquinated htt in the nuclear space. ${ }^{64,67}$ Striatal neurons have fewer NI than the cortex, indicating a possible decrease in protective function. ${ }^{68,69}$ Moreover, NI might be a marker of abnormal htt metabolism unrelated to cellular dysfunction. ${ }^{70}$ Selective, tissue specific, cleavage of htt has been shown to produce varying effects on NI and neuropil aggregates. ${ }^{71-73}$ Using cysteine aspartate-specific proteases (caspase) inhibitors, NI and neuropil aggregates were reduced without affecting survival in striatal cell cultures expressing mutant and wild type htt. Using the YAC model of $\mathrm{HD}$, Hodgson et $\mathrm{al}^{74}$ showed electrophysiological changes and neuronal loss prior to formation of N1.

Aggregates outside the nucleus may also contribute to HD pathogenesis. Gutekunst et $\mathrm{al}^{69}$ have described the formation of aggregates in the neuropil in presymptomatic HD. Furthermore, R6 transgenic mice have been shown to produce similar aggregates in their axons, ${ }^{75}$ with the amount showing a positive correlation with disease progression.

From this data one can only conclude that aggregate formation is incompletely understood. Previous hypotheses that these formations represent the common pathogenesis leading to neurodegeneration have been questioned, and other mechanisms of toxicity, such as toxic fragment theory have surfaced. ${ }^{76}$

Huntingtin has been shown to be a substrate for caspase activity, ${ }^{77}$ proteases that are activated to effect programmed cell death (apoptosis) and inflammatory responses. ${ }^{78}$ Proteolysis of htt might produce fragments with caspase interacting domains having a proapoptotic effect. ${ }^{79}$ Creation of a caspase resistant htt has provided some direct evidence that htt-caspase interaction is a necessary step in the toxic effects of htt. ${ }^{80}$ This interaction is potentially through the unique epitope produced by the polyQ expansion. ${ }^{81}$ In addition, the translocation of the htt $\mathrm{N}$-terminal fragments into the nucleus of YAC mice models correlates with neuronal dysfunction. ${ }^{74}$

There has been increasing evidence that wild-type htt has a protective role in neuron survival. It has been shown to have anti-apoptotic properties in striatal derived cells and other tissue high in htt expression. ${ }^{82,83}$ Huntingtin has been found to bind to a number of cellular proteins like Huntingtin interacting protein $1,{ }^{84}$ which has been found to be proapoptotic via a possible death effecter domain. Mutant htt is less effective at blocking this role, thereby increasing "free" Huntingtin interacting protein 1.

Mitochondrial dysfunction continues to be a model for HD pathophysiology, ${ }^{85,86}$ and a number of animal models use mitochondrial toxins to cause neuron death through indirect excitotoxicity. A commonly used mitochondrial toxin in HD animal models is 3-nitropropionate, a mitochondrial enzyme inhibitor. ${ }^{87}$ 3-Nitropropionate is a naturally occurring toxin and has caused chronic movement disorders in humans. ${ }^{88}$ Intrastriatal and systemic administration of 3-nitropropionate has been found to produce behavioural and neuropathological findings in rats and mice that are similar to HD. ${ }^{89,90}$ Furthermore, studies in HD patients have shown alterations in the metabolic activity in muscle tissue ${ }^{6}$ as well as the basal ganglia. ${ }^{91}$ However, genetic mice models have shown normal mitochondrial complex (I-IV) activity in the early symptomatic period..$^{22}$

Coenzyme Q10, a carrier in the mitochondrial electron transport chain, has been shown to block the actions of a mitochondrial toxin in mice. ${ }^{93}$ Furthermore, combination therapy with coenzyme Q10 and remacemide has been shown to significantly increase survival in the R6/2 and N171-82Q mouse models by $31.8 \% .{ }^{94}$ However, human therapeutic trials have not been successful. In a recent double blind randomized control 
trial, administration of coenzyme Q10 with or without remacemide, did not produce significant slowing in functional decline in HD subjects. ${ }^{95}$ It remains to be shown what role mitochondrial dysfunction might play in HD pathogenesis and what therapeutic effect medications like coenzyme Q10, might have.

\section{Management}

As there is no treatment to arrest the chronic progression of HD, clinical efforts are focused on symptom relief and supportive management, and require a multidisciplinary team with skills in managing the challenges faced by the patient and family members.

Abnormal movements may be suppressed with neuroleptics, which have the added benefit of controlling psychiatric symptomatology. In the past, drugs such as haloperidol were the standard therapy ${ }^{96}$ but carry the risk of worsening bradykinesia, gait and balance problems. Atypical neuroleptics, such as rispiridone and olanzapine, are now used preferentially, based on open label trials and a lower side effect profile. ${ }^{97-99}$ Tetrabenazine, a presynaptic dopamine depleting agent, has been shown to be of use but may result in depression. ${ }^{96}$ Very recently, a randomized controlled trial with amantadine resulted in significant improvement in chorea, with minimal side effects. ${ }^{100}$

Treatment of HD must address the risk of patient depression, affecting up to $22 \%$ of patients in the first year after diagnosis and remaining high throughout the course of the illness. ${ }^{1,7}$ Antidepressants, including selective serotonin reuptake inhibitors and tricyclics, can be used successfully. In all cases, risk assessment for suicide should be performed at each visit. Effective management of mental disturbances in patients may require psychiatric intervention and such care should be part of the treatment plan for all patients.

The major purpose of these symptom relief measures is to improve quality of life. It is important to recognize that supporting the patient's family and care-givers is another critical feature of successful care. Aggressive use of physiotherapy, occupational therapy, and home care can prolong the ability of care-givers to manage the patient's needs at home. Additional support from social services, dietary, and speech therapy can be added to the treatment plan as needed. Lastly, legal issues regarding guardianship and management of financial affairs must be dealt with.

Based on animal models, a number of agents have recently been postulated to have neuroprotective effects. Creatine has been shown to have activity in slowing disease progression in R6/2 mice. ${ }^{101,102}$ Minocycline, a caspase synthesis inhibiting antibiotic, has significant effects in mouse models as well. ${ }^{103}$ Human studies to evaluate the clinical efficacy of these compounds are underway. Recent trials designed to reduce oxidative stress, and alter glutamate metabolism, using lamotrigine, remacemide, and coenzyme Q10, have not shown a clinical benefit. ${ }^{95,104}$ Thus, at this time, no recommendations can be made to patients with respect to effective neuroprotective therapies.

There is currently no routine indication for the use of neurosurgery in the treatment of $\mathrm{HD}$, although transplantation of neural tissue has shown some promise in animal models resulting in motor and cognitive improvement. ${ }^{105}$ Early studies with HD patients have focused on safety and long-term viability of the grafts. ${ }^{106}$ Tacit benefit, or slowing of decline, was seen in one study with a small study population, providing a basis for further research. ${ }^{107}$ Others are exploring novel targets for deep brain stimulators to provide symptomatic relief. ${ }^{108,109}$ However, the potential effectiveness of these interventions is limited due to the widespread pathology in HD.

A recent paper using a unique experimental mouse model of HD has provided a new approach to the potential of medical therapy. ${ }^{110}$ This mouse model allows for the selective expression or inactivation of a truncated HD gene containing the expanded CAG repeat sequence. The mice developed significant pathologic and behavioural changes consistent with their HD phenotype. When htt expression was suppressed, pathologic changes where halted and even reversed. Furthermore, the abnormal behavioural phenotype significantly improved. Thus, this type of genetic engineering may provide a successful therapeutic intervention.

\section{Conclusion}

Research continues to extend our understanding of the genetics, pathophysiology, and treatment options for HD, with the hope that a curative treatment will soon be possible. Huntington's disease remains a challenging disease to treat due to its significant morbidity, and effects on the whole family. Currently, treatment efforts are aimed at providing optimal supportive care through a coordinated team of physicians, nurses, social workers, and ancillary medical staff. The heavy psychological toll on the patient and family requires accessible counseling and psychiatric services. The Huntington Society of Canada (www.hsc-ca.org), and other reputable information sources, can form an additional link for persons affected by HD and information on health resources.

\section{REFERENCES}

1. Harper PS. Huntington's Disease. London: WB Saunders Co. Ltd., 1991: 1-15.

2. Huntington G. On chorea. Med Surg Reports 1872; 26: 320-321.

3. Folstein SE, Chase GA, Wahl WE, et al. Huntington's disease in Maryland: clinical aspects of racial variation. Am J Hum Genet 1987; 41: 168-179.

4. Vessie PR. On the transmission of Huntington chorea for 300 years: the Bures family group. J Nerv Ment Dis 1932; 76: 553.

5. Sanberg PR, Fibiger MC, Mark RF. Body weight and dietary factors in Huntington's disease patients compared with matched controls. Med J Australia 1981; 1: 407-409.

6. Lodi R, Schapira AH, Manners D, et al. Abnormal in vivo skeletal muscle energy metabolism in Huntington's disease and dentatorubropallidoluysian atrophy. Ann Neurol 2000; 48: 72-76.

7. Kirkwood SC, Su JL, Conneally PM, Foroud T. Progression of symptoms in the early and middle stages of Huntington's disease. Arch Neurol 2001; 58: 273-278.

8. Snowden J, Craufurd D, Griffiths H, Thompson J, Neary D. Longitudinal evaluation of cognitive disorder in Huntington's disease. J Int Neuropsychol Soc 2001; 7: 33-44.

9. Reuter I, Hu MTM, Andrew TC, et al. Late onset levodopa responsive Huntington's disease with minimal chorea masquerading as Parkinson plus syndrome. J Neurol Neurosurg Psychiatry 2000; 68: 238-241.

10. Gomez-Tortosa E, MacDonald ME, Friend JC, et al. Quantitative neuropathological changes in presymptomatic Huntington's disease. Ann Neurol 2001; 49: 29-34.

11. Aylward EH, Codori AM, Rosenblatt A, et al. Rate of caudate 
atrophy in presymptomatic and symptomatic stages of Huntington's disease. Mov Disord 2000; 15: 552-560.

12. Young AB, Penney JB, Staroster-Rubinstein S, et al. PET Scan investigations of Huntington's disease: cerebral metabolic correlates of neurological features and functional decline. Ann Neurol 1986; 20: 296-303.

13. Reynolds NC Jr, Hellman RS, Tikofsky RS, et al. Single photon emission computerized tomography (SPECT) in detecting neurodegeneration in Huntington's disease. Nucl Med Commun 2002; 23:13-18.

14. Feigin A, Leenders KL, Moeller JR, et al. Metabolic network abnormalities in early Huntington's disease: an [(18)F]FDG PET study. J Nucl Med 2001; 42: 1591-1595.

15. Clark VP, Lai S, Deckel AW. Altered functional MRI responses in Huntington's disease. Neuroreport 2002; 13:703-705.

16. The Huntington's Disease Collaborative Group. A novel gene containing a trinucleotide repeat that is expanded and unstable on Huntington's disease chromosomes. Cell 1993; 72: 971-983.

17. Strong TV, Tagle DA, Valdes JM, et al. Widespread expression of the human and rat Huntington's disease gene in brain and nonneural tissues. Nat Genet 1993; 5: 259-265.

18. Duyao M, Ambrose C, Myers R, et al. Trinucleotide repeat length instability and age of onset in Huntington's disease. Nat Genet 1993; 4: 387-392.

19. Furtado S, Suchowersky O, Rewcastle NB, et al. The relationship of the trinucleotide repeat sequences and neuropathological changes in Huntington's disease. Ann Neurol 1996; 39: 132-136.

20. Zuhlke C, Riess O, Bockel B, Lange H, Thies U. Mitotic stability and meiotic variability of the (CAG) $n$ repeat in the Huntington disease gene. Hum Mol Genet 1993; 2: 2063-2067.

21. Wexler NS, Young AB, Tanzi RE, et al. Homozygotes for Huntington's disease. Nature 1987; 326: 194-197.

22. Myers RM, MacDonald ME, Koroschetz WJ, et al. Denovo expansion of a (CAG)n repeat in sporadic Huntington's disease. Nat Genet 1993; 5: 168-173.

23. Margolis RL, O'Hearn E, Rosenblatt A, et al. A disorder similar to Huntington's disease is associated with a novel CAG repeat expansion. Ann Neurol 2001; 50: 373-380.

24. Xiang F, Almquist EW, Huq M, et al. A Huntington disease-like neurodegenerative disorder maps to Chromosome 20p. Am J Hum Genet 1998; 63: 1431-1438.

25. Kambouris M, Bohlega S, Al-Tahan A, Meyer BF. Localization of the gene for a novel autosomal recessive neurodegenerative Huntington-like disorder to 4p15.3. Am J Hum Genet 2000; 66:445-452.

26. Richfield EK, Vonsattel JP, MacDonald ME, et al. Selective loss of striatal preprotachykinin neurons in a phenocopy of Huntington's disease. Mov Disord 2002; 17:327-332.

27. Margolis RL, O'Hearn E, Rosenblatt A, et al. A disorder similar to Huntington's disease is associated with a novel CAG repeat expansion. Ann Neurol 2001; 50: 373-380.

28. Stevanin G, Camuzat A, Holmes SE, et al. CAG/CTG repeat expansions at the Huntington's disease-like 2 locus are rare in Huntington's disease patients. Neurol 2002; 58: 965-967.

29. Mangiarini L, Sathasivam K, Seller M, et al. Exon 1 of the HD gene with an expanded CAG repeat is sufficient to cause a progressive neurological phenotype in transgenic mice. Cell 1996; 87: 493-506.

30. Schilling G, Becher MW, Sharp AH, et al. Intranuclear inclusions and neuritic aggregates in transgenic mice expressing a mutant $\mathrm{N}$ terminal fragment of huntingtin. Hum Mol Genet 1999; 8: 397-407.

31. Reddy PH, Williams M, Charles V, et al. Behavioural abnormalities and selective neuronal loss in HD transgenic mice expressing mutated full-length HD cDNA. Nat Genet 1998; 20: 198-202.

32. Hodgson J, Agopyan N, Gutekunst C-A, et al. AYAC mouse model for Huntington's disease with full-length mutant huntingtin, cytoplasmic toxicity, and selective striatal neurodegeneration. Neuron 1999; 23: 181-192.

33. White JK, Auerbach W, Duyao MP, et al. Huntingtin is required for neurogenesis and is not impaired by the Huntington's disease CAG expansion. Nat Genet 1997; 17: 404-410.
34. Shelbourne PF, Killeen N, Hevner RF, et al. A Huntington's disease CAG expansion at the murine $\mathrm{Hdh}$ locus is unstable and associated with behavioral abnormalities in mice. Hum Mol Genet 1999; 8: 763-774.

35. Wheeler VC, Auerbach W, White JK, et al. Length-dependent gametic CAG repeat instability in the Huntington's disease knock-in mouse. Hum Mol Genet 1999; 8: 115-122.

36. Wheeler VC, White JK, Gutekunst C-A, et al. Long glutamine tracts cause nuclear localization of a novel form of huntingtin in medium spiny striatal neurons in HdhQ92 and HdhQ111 knockin mice. Hum Mol Genet 2000; 9: 503-513.

37. Lione LA, Carter RJ, Hunt MJ, et al. Selective discrimination learning impairments in mice expressing the human Huntington's disease mutation. J Neurosci 1999; 19: 10428-10437.

38. Carter RJ, Lione LA, Humby $\mathrm{T}$, et al. Characterization of progressive motor deficits in mice transgenic for the human Huntington's disease mutation. J Neurosci 1999; 19: 3248-3257.

39. Jackson GR, Salecker I, Dong X, et al. Polyglutamine-expanded human huntingtin transgenes induced degeneration of Drosophila photoreceptor neurons. Neuron 1998; 21: 633-642.

40. Faber PW, Alter JR, MacDonald ME, Hart AC. Polyglutaminemediated dysfunction and apoptotic death of a Caenorhabditis elegans sensory neuron. Proc Natl Acad Sci U S A 1999; 96: 179184.

41. Almqvist EW, Bloch M, et al. A worldwide assessment of the frequency of suicide, suicide attempts, or psychiatric hospitalization after predictive testing for Huntington disease. Am J Hum Genet 1999; 64: 1293-1304.

42. Simpson SA, Harper PS. Prenatal testing for Huntington's disease: experience within the UK 1994-1998. J Med Genet 2001; 38: 333-335.

43. Vonsattel JM, Myers RH, Stevens TJ, et al. Neuropathological classification of Huntington's disease. J Neuropathol Exp Neurol 1985;44:559-577.

44. Rodda RA. Cerebellar atrophy in Huntington's disease. J Neurol Sci 1981; 50: 147-157.

45. Hedreen JC, Peyser CE, Folstein SE, Ross CA. Neuronal loss in layers V and VI of cerebral cortex in Huntington's disease. Neurosci Lett 1991; 133: 257-261.

46. Jackson M, Gentleman S, Lennox G, et al. The cortical neuritic pathology of Huntington's disease. Neuropathol Appl Neurobiol 1995; 21: 18-26.

47. Difiglia M. Excitotoxic injury of the neostriatum is a model for Huntington's disease. Trends Neurosci 1990; 13: 286-289.

48. McGeer EG, McGeer PL. Duplication of biochemical changes of Huntington's chorea by intrastriatal injections of glutamic acid and kainic acid. Nature 1976; 263: 517-519.

49. Beal MF, Kowall NW, Ellison DW, et al. Replication of the neurochemical characteristics of Huntington's disease by quinolinic acid. Nature 1986; 321: 163-171.

50. Coyle JT, Puttfarcken P. Oxidative stress, glutamate and neurodegenerative disorders. Science 1993; 262: 689-695.

51. Wolfensberger M, Amsler V, Cuenod M, et al. Identification of quinolinic acid in rat and human brain tissue. Neurosci Lett 1983; 41: 247-252

52. Nicholson LF, Faull RL, Waldvogel HJ, Dragunow M. GABAand GABA A receptor changes in the substantia nigra of the rat following quinolinic acid lesions in the striatum closely resemble Huntington's disease. Neuroscience 1995; 66: 507-521.

53. Ferrante RJ, Kowall NW, Cipolloni PB, Storey E, Beal MF. Excitotoxin lesions in primates as a model for Huntington's disease: histopathologic and neurochemical characterization. Exp Neurol 1993; 119: 46-71.

54. Guidetti P, Charles V, Chen E, et al. Early degenerative changes in transgenic mice expressing mutant huntingtin involve dendritic abnormalities but no impairment of mitochondrial energy production. Exp Neurol 2001; 169: 340-350.

55. Metzler M, Chen N, Helgason CD, et al. Life without huntingtin: normal differentiation into functional neurons. Neurochemistry 1999; 72: 1009-1018.

56. Hilditch-Maguire P, Trettel F, Passani LA, et al. Huntingtin: an iron-regulated protein essential for normal nuclear and 
perinuclear organelles. Hum Mol Genet 2000; 9: 2789-2797.

57. Iannicola C, Moreno S, Oliverio S, et al. Early alterations in gene expression and cell morphology in a mouse model of Huntington's Disease. J Neurochem 2000; 75: 830-839.

58. Cha JH, Kosinski CM, Kerner JA, et al. Altered brain neurotransmitter receptors in transgenic mice expressing a portion of an abnormal human huntington disease gene. Proc Natl Acad Sci USA. 1998; 95:6480-6485.

59. Saudou F, Finkbeiner S, Devys D, Greenberg ME. Huntingtin acts in the nucleus to induce apoptosis but death does not correlate with formation of intranuclear inclusions. Cell 1998; 95: 55-66.

60. Zuccato C, Ciammola A, Rigamonti D, et al. Loss of Huntingtinmediated BDNF gene transcription in Huntington's disease. Science 2001; 293: 493-498.

61. Dunah AW, Jeong H, Griffin A, et al. Sp1 and TAFII130 transcriptional activity disrupted in early Huntington's disease. Science 2002; 296:2238-2243.

62. Davies SW, Turmaine M, Cozens BA, et al. Formation of neuronal intranuclear inclusions underlies the neurological dysfunction in mice transgenic for the HD mutation. Cell 1997; 90: 537-548.

63. Difiglia M, Sapp E, Chase KO, et al. Aggregation of huntingtin in neuronal intranuclear inclusions and dystrophic neurites in brain. Science 1997; 277: 1990-1993.

64. Ferrigno P, Silver PA. Polyglutamine expansions: proteolysis, chaperones, and the dangers of promiscuity. Neuron 2000; 26: 912.

65. Roizin L, Stellar S, Liu JC. Neuronal nuclear-cytoplasmic changes in Huntington's chorea: electron microscope investigations. Adv Neurol 1979; 23: 95-122.

66. Roos RAC, Bots GTAM. Nuclear membrane indentations in Huntington's chorea. J Neurol Sci 1983; 61: 37-47.

67. Ordway JM, Tallaksen-Greene S, Gutekunst CA, et al. Ectopically expressed CAG repeats caused intranuclear inclusions and a progressive late onset neurological phenotype in the mouse. Cell 1997; 91: 753-763.

68. Kuemmerle S, Gutekunst CA, Klein AM, et al. Huntingtin aggregates may not predict neuronal death in Huntington's disease. Ann Neurol 1999; 46: 842-849.

69. Gutekunst $\mathrm{CA}, \mathrm{Li} \mathrm{SH}, \mathrm{Yi} \mathrm{H}$, et al. Nuclear and neuropil aggregates in Huntington's disease: relationship to neuropathology. J Neurosci 1999; 19: 2522-2534.

70. Kim M, Lee H-S, LaForet G, et al. Mutant huntingtin expression in clonal striatal cells: dissociation of inclusion formation and neuronal survival by caspase inhibition. J Neurosci 1999; 19: 964-973.

71. Cooper JK, Schilling G, Peters MF, et al. Truncated N-terminal fragments of huntingtin with expanded glutamine repeats form nuclear and cytoplasmic aggregates in cell culture. Hum Mol Genet 1998; 7: 783-790.

72. Hackam A, Singaraja T, Wellington CL, et al. The influence of huntingtin protein size on nuclear localization and cellular toxicity. J Cell Biol 1998; 141: 1097-1105.

73. Wellington CL, Ellerby LM, Hackam AS, et al. Caspase cleavage of gene products associated with triplet expansion disorders generates truncated fragments containing the polyglutamine tract. J Biol Chem 1998; 273: 9158-9167.

74. Hodgson JG, Agopyan N, Gutekunst C-A, et al. A YAC mouse model for Huntington's disease with full-length mutant huntingtin, cytoplasmic toxicity, and selective striatal neurodegeneration. Neuron 1999; 23:181-192.

75. $\mathrm{Li} \mathrm{H}, \mathrm{Li} \mathrm{SH}$, Cheng AL, et al. Ultrastructural localization and progressive formation of neuropil aggregates in Huntington's disease transgenic mice. Hum Mol Gen 1999; 8:1227-1236.

76. Wellington CL, Hayden MR. Of molecular interactions, mice and mechanisms: new insights into Huntington's disease. Curr Opin Neurol 1997; 10: 291-298.

77. Wellington CL, Ellerby LM, Hackam AS, et al. Caspase cleavage of gene products associated with triplet expansion disorders generates truncated fragments containing the polyglutamine tract. J Biol Chem 1998; 273: 9158-9167.

78. Nuñez G, Benedict MA, Hu Y, Inohara N. Caspases: the proteases of the apoptotic pathway. Oncogene 1998; 17: 3237-3245.
79. Wellington CL, Hayden MR. Caspases and neurodegeneration: on the cutting edge of new therapeutic approaches. Clin Genet 2000; 57: $1-10$.

80. Wellington CL, Singaraja R, Ellerby L, et al. Inhibition of caspase cleavage of huntingtin protects neurons from toxicity and aggregate formation. Am J Hum Genet 1999; 65: A4.

81. Trottier Y, Lutz Y, Stevanin G, et al. Polyglutamate expansion as a pathological epitope in Huntington's disease and four dominant cerebellar ataxias. Nature 1995; 378:403-406.

82. Rigamonti D, Bauer JH, De-Fraja C, et al. Wild-type huntingtin protects from apoptosis upstream of caspase-3. J Neurosci 2000; 20: 3705-3713.

83. Leavitt BR, Guttman JA, Hodgson JG, et al. Wild-type huntingtin reduces the cellular toxicity of mutant huntingtin in vivo. Am J Hum Genet 2001; 68: 313-324.

84. Hackam AS, Yassa AS, Singaraja R. Huntingtin Interacting Protein 1 induces apoptosis via a novel caspase-dependent death effector domain. J Biol Chem 2000; 275: 41299-41308.

85. Brouillet E, Conde F, Beal MF, Hantraye P. Replicating Huntington's disease phenotype in experimental animals. Prog Neurobiol 1999; 59: 427-468.

86. Beal MF. Does impairment of energy metabolism result in excitotoxic neuronal death in neurodegenerative illnesses? Ann Neurol 1992; 31: 119-130.

87. Coles CJ, Edmonson DE, Singer TP. Inactivation of succinate dehydrogenase by 3-nitropropionate. J Biol Chem 1979; 255: 4772-4780.

88. Peraica M, Radic B, Lucic A, Pavlovic M. Toxic effects of mycotoxins in humans. Bull World Health Org 1999; 77: 754766.

89. Beal MF, Brouillet FE, Jenkins BG, et al. Neurochemical and histologic characterization of striatal excitotoxic lesions produced by the mitochondrial toxin 3-nitropropionic acid. J Neurosci 1993; 13: 4186-4192.

90. Borlongan CV, Koutouzis TK, Freeman TB, Cahill DW, Sanberg PR. Behavioral pathology induced by repeated systemic injections of 3-nitropropionic acid mimics the motor symptoms of Huntington's disease. Brain Res 1995; 697: 254-257.

91. Gu M, Gash MT, Mann VM, et al. Mitochondrial defect in Huntington's disease caudate nucleus. Ann Neurol 1996; 39: 385389.

92. Ellison DW, Beal MF, Mazurek MF, et al. Amino acid neurotransmitter abnormalities in Huntington's disease and the quinolinic acid animal model of Huntington's disease. Brain 1987; 110: 1657-1673.

93. Beal MF, Henshaw DR, Jenkins BG, Rosen BR, Schulz JB. Coenzyme Q10 and nicotinamide block striatal lesions produced by the mitochondrial toxin Malonate. Ann Neurol 1994; 36: 882888.

94. Ferrante RJ, Andreassen OA, Dedeoglu A, et al. Therapeutic effects of coenzyme Q10 and remacemide in transgenic mouse models of Huntington's disease. J Neurosci 2002; 22:1592-1599.

95. The Huntington Study Group. A randomized, placebo-controlled trial of coenzyme Q10 and remacemide in Huntington's disease. Neurology 2001; 57: 397-404.

96. Gimenez-Roldan S, Mateo D. Huntington disease: tetrabenazine compared to haloperidol in the reduction of involuntary movements. Neurologia 1989; 4: 282-287.

97. Bogelman G, Hirschmann S, Modai I. Olanzapine and Huntington's disease. J Clin Psychopharmacol 2001; 21:245-246.

98. Dallocchio C, Buffa C, Tinelli C, Mazzarello P. Effectiveness of risperidone in Huntington chorea patients. J Clin Psychopharmacol 1999; 19(1):101-103.

99. Parsa MA, Szigethy E, Voci JM, Meltzer HY. Risperidone in treatment of choreoathetosis of Huntington's disease. J Clin Psychopharmacol 1997; 17(2):134-135.

100. Metman LV, Morris MJ, Farmer C, et al. Huntington's disease: a randomized, controlled trial using the NMDA-antagonist amantadine. Neurology 2002; 59: 694-699.

101. Ferrante RJ, Andreassen OA, Jenkins BG, et al. Neuroprotective effects of creatine in a transgenic mouse model of Huntington's disease. J Neurosci 2000; 20; 4389-4397. 
102. Anderassen OA, et al. Creatine increases survival and delays motor symptoms in a transgenic animal model of Huntington's disease. Neurobiol Dis 2001; 8: 479-491.

103. Chen M, et al. Minocycline inhibits caspase- 1 and caspase- 3 expression and delays mortality in a transgenic mouse model of Huntington disease. Nat Med 2000; 6: 797-801.

104. Kremer B, Clark CM, Almqvist EW, et al. Influence of lamotrigine on progression of early Huntington's disease: a randomized clinical trial. Neurology 1999; 53: 1000-1011

105. Palfi S, Conde F, Riche D, et al. Fetal striatal allografts reverse cognitive deficits in a primate model of Huntington disease. Nat Med 1998; 4:727-729.

106. Hauser RA, Furtado S, Cimino CR, et al. Bilateral human fetal striatal transplantation in Huntington's disease. Neurology 2002; 58: 687-695.

107. Bachoud-Lefi AC, Remy P, Nguyen JP, et al. Motor and cognitive improvements in patients with Huntington's disease after neural transplantation. Lancet 2000; 356: 1975-1979.

108. Bonelli RM, Gruber A. Deep brain stimulation in Huntington's disease. Mov Disord 2002;17: 429-430.

109. Joel D. Open interconnected model of basal ganglia-thalamocortical circuitry and it's relevance to the clinical syndrome of Huntington's disease. Mov Disord 2001; 16: 407-423.

110. Yamamoto A, Lucas JJ, Hen R. Reversal of a neuropathology and motor dysfunction in a conditional model of Huntington's disease. Cell 2000; 101: 57-66. 